\title{
Pilot-Scale Evaluation of Engineered Barrier Systems for the Yucca Mountain Project
}

\author{
S.W. Webb, J.T. George \& R.E. Finley \\ Sandia National Laboratories, Albuquerque, New Mexico, United States
}

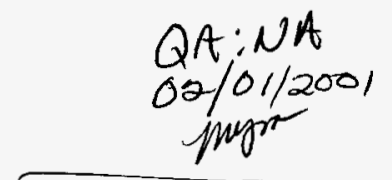

MOL. 20010504.0199

\begin{abstract}
This paper describes two quarter-scale experiments $(1.4 \mathrm{~m}$ diameter $)$ and associated numerical analyses on granular backfill engineered barrier systems in support of the Yucca Mountain Project for the potential repository. The two configurations include a sloped capillary barrier and a plain backfill. The tests involve application of dyed water as a constant line infiltration source along the top of the test set-up, monitoring water movement through the test, and measuring water exiting the experiments. A complete water balance estimate is made for each test, and observed water movement is compared with (1) detailed numerical analyses conducted using the TOUGH2 code for unsaturated flow in porous media and (2) posttest observations. The results of the testing and analyses show that for the injection rates and configuration applied, the capillary barrier design diverts a significant amount of all injected water and the TOUGH2 pretest predictions show qualitative and quantitative agreement with the experimental data.
\end{abstract}

\section{INTRODUCTION}

The Yucca Mountain Project (YMP) is currently developing the Site Recommendation (SR) design for the underground facilities including the emplacement drifts and the Engineered Barrier Systems (EBS) components within them. The SR design includes alternative configurations for key subsystems that will demonstrate the ability of the design to accommodate unexpected conditions. Beginning in 1999, possible design configurations were explored using scaled models. The Pilot Scale ( $1 / 4$ scale) experiments described here are intended to develop an engineering assessment of the viability of key engineered barrier components for use at YMP. The first two Pilot Scale experiments are (1) a capillary barrier consisting of a fine granular material overlying a coarse granular material, and (2) a standard coarse granular backfill. Neither the capillary barrier nor backfill are part of the current repository design but may be added at a later date. The current repository design uses a drip shield to protect the waste packages from rock falls and water intrusion.

Capillary barrier test data and observations are presented for the first 70 days of testing as the barrier is initially stressed by the infiltrating water. The plain backfill test was operated for only approximately 34 days as downward infiltrating water quickly contacted the simulated waste package.
A limited database of information exists regarding backfill behavior. Backfill has long been used in the mining industries to stabilize mine workings and as a convenient method for disposing of waste rock. Little is known about the thermal or coupled themalhydrological-mechanical-chemical processes that are likely to occur within backfill systems for the YMP. The only large-scale data currently available for crushed tuff backfill materials at elevated temperatures and scales appropriate for the YMP were obtained by Ryder et al. (1996), who evaluated the thermal behavior of coarse crushed tuff backfill. Fernandez and Richardson (1994) evaluated available technologies for sealing the potential repository at Yucca Mountain, including technologies for emplacing backfill materials. A significant literature base exists for the thermal behavior of two-phase (rock and air) systems or porous beds, as discussed in Kaviany (1991). Capillary barriers have been considered as alternative engineered barrier systems for backfilling of emplacement drifts by Conca et al. (1998). Capillary barriers have also been extensively studied as alternative approaches to landfill cover systems, particularly in arid environments (e.g. Webb 1997a, 1997b; Ho and Webb 1998a, 1998b; Stormont 1995a, 1995b; Ross 1990; Oldenberg and Pruess 1993), although little is known regarding their long-term performance or response to thermal effects. 


\section{EBS PILOT-SCALE TEST CONFIGURATION}

Each of the two engineered barrier system experiments described here were conducted at approximately $1 / 4$ scale and relied on simplified instrumentation configurations and visual observations within steel containers. These engineering demonstration tests will resolve key uncertainties in the behavior of potential alternative backfill systems at ambient temperatures. The tests are conducted at approximately $1 / 4$ scale to evaluate performance at a scale larger than can be conducted in the laboratory and to evaluate three-dimensional and heterogeneity effects. The test cell length and diameter are scaled approximately proportionally at $1 / 4$ scale, and the slope of the test cell is approximately the same slope as the anticipated slope of the emplacement drifts (0.5 to $1 \%)$. This configuration results in a nominal test cell (cylinder) diameter of $1.4 \mathrm{~m}$ and a length of $4 \mathrm{~m}$ with the ends sealed.

The infiltration condition for the tests is a rate equivalent to about $250 \mathrm{~mL} / \mathrm{hr} / \mathrm{m}$ length of test cell. Such a flow rate allows evaluation of the performance of the EBS systems in a timely manner without unduly stressing the experiments.

Figure 1 shows the capillary barrier configuration (EBS Test \#1) for these initial $1 / 4$ scale tests in crosssection with approximate locations of instrumentation and drainage ports. The plain backfill configuration is similar with the exception that no fine upper layer exists and the coarse backfill extends to the top of the sloped area shown in the figure. In general, the top of the backfill in both cases extended to within about $0.15 \mathrm{~m}$ of the top of the steel container. The slopes of the barriers were placed at nominally $30^{\circ}$. The nominal thickness of the capillary barrier layer was about $0.3 \mathrm{~m}$. A simulated waste package constructed from a clear acrylic tube was placed as shown in the figure. This tube allowed access with a camera system to visually observe infiltrated water contacting the package. Also included in the test setup were braided fiberglass wicks which were placed along the outer boundaries of the canister that were intended to provide a constant suction boundary condition and to provide a means for the water to be drained from the system. Water removed from the wicks was weighed for inclusion in the water balance estimates.

The approach for instrumentation and diagnostics in the EBS Pilot Scale engineering demonstration tests was to "simplify." The primary purpose of the Pilot Scale testing is to determine "where the water went" and whether any water contacted the simulated waste packages. With the above two concepts in mind, the instrumentation and diagnostics were capable of visualizing the water contacting the simulated waste package, measuring the environment (relative humidity, saturation, and temperature) within the backfill and test container, and measuring the water input and output (water balance). Gauges for the tests include nine Omega Resistance Temperature Devices (RTDs) installed on the outer surface of the container, nine Vaisala temperature/ humidity probes installed inside each container (with three probes monitoring the air space above the placed backfill and six probes installed within the backfill surrounding the clear acrylic visualization tube), six HBM tank weigh modules (TWMs) installed within the support cradle of each container to monitor the weight and weight change of the backfill system, and three GSE platform scales used to monitor the weight of the injected fluid into the container.

The primary test controls for the tests include the test cell geometry, water injection rate and location, ventilation control, thermal control of the waste package and test cell shell, and control of the suction boundary condition where the fine layer contacts the test container. Injection of water is accomplished by discrete injection points located on the top of each container.

The discharge of liquid water from the test system is likewise controlled and monitored. Discharge from the natural system will largely occur through unsaturated fractures intersecting the drift walls or by saturated fracture flow from ponded water in the bottom of the drift. These modes of discharge are simulated in the tests by drains installed along the base of the test apparatus, suction wicks installed in small holes along the sides of the test cell, and suction lysimeters. Gravity drainage is accommodated though ports drilled through the bottom of the test cell using engineered wicks. The location, amount, and timing of gravity drainage were measured throughout the experiment.

\subsection{Material Description}

This section defines the backfill materials used for the tests.

Capillary Barrier:

Fine fraction backfill: Overton sand (\#50-\#70 sieve) from local source. Porosity and permeability of 0.38 and $1.4 \times 10^{-11} \mathrm{~m}^{2}$ used for modeling purposes.

Coarse fraction backfill: Coarse sand from a local Las Vegas supplier, \#8-20 sand (sand passing the \#8 and retained on the \#20 sieve). Porosity and permeability of 0.38 and $5.4 \times 10^{-11} \mathrm{~m}^{2}$ used for modeling purposes. 


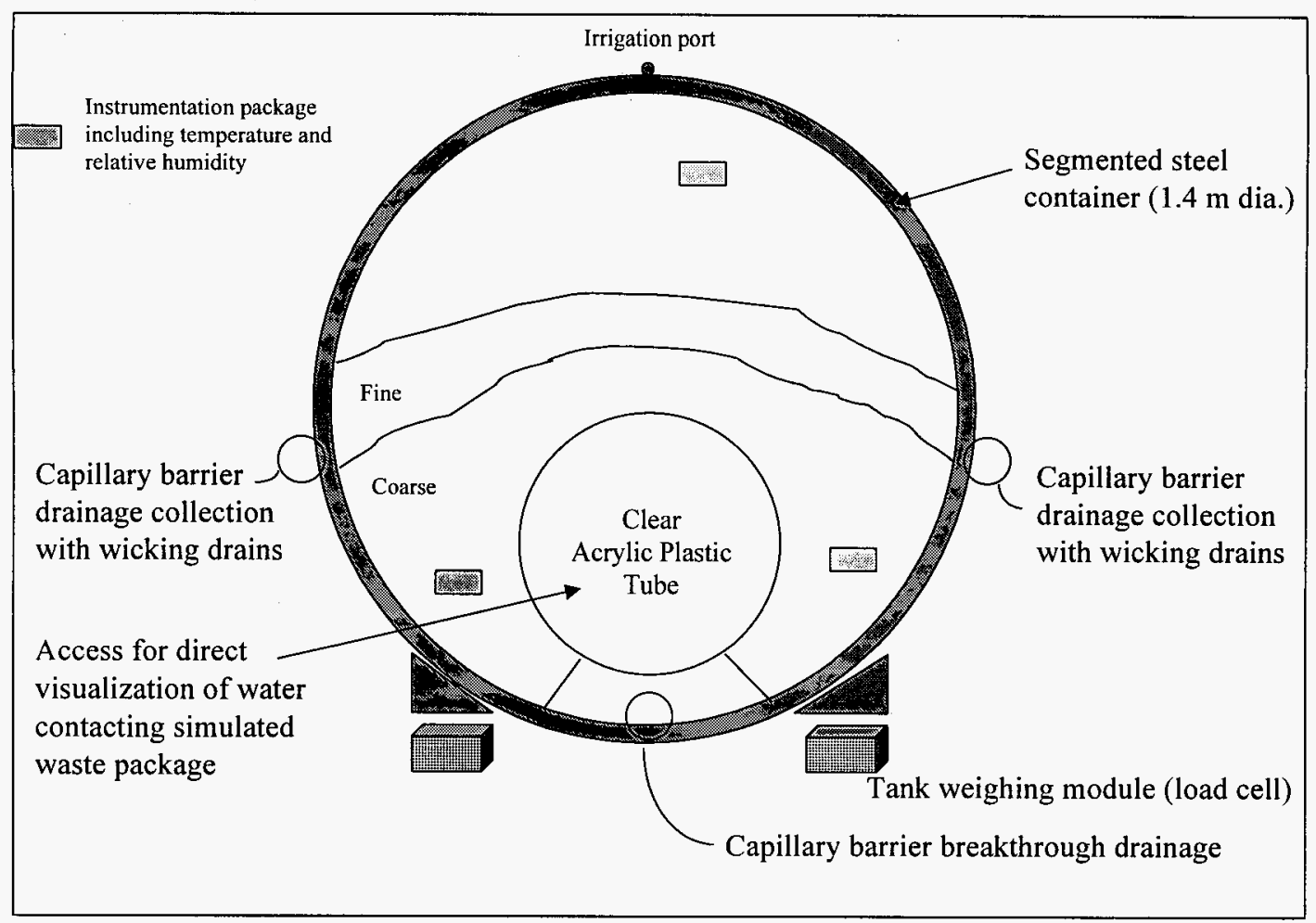

Figure 1. Cross-Section View of Ambient Capillary Barrier $1 / 4$ Scale Configuration.

Plain Backfill:

Coarse granular backfill: Coarse sand from a local Las Vegas supplier, \#10-20 sand (sand passing the $\# 10$ and retained on the \#20 sieve). Porosity and permeability of 0.38 and $5.4 \times 10^{-11} \mathrm{~m}^{2}$ used for modeling purposes.

\subsection{Injection System}

The EBS test water injection system was developed to provide controllable, uniform, precise liquid injection (water with $500 \mathrm{ppm}$ fluorescein dye) to multiple points in the test canisters. The basic components of the system are the distributed injection point array, the injection syringe pumps, tracer fluid reservoirs, and the tracer weighing system. A single line of injection points across the top of the canister was used. This configuration emulates a fracture, collecting the infiltration from mid-pillar to midpillar and concentrating it on the centerline of the test canister. Liquid tracer is injected into each test canister through 30 injection points uniformly spaced along the top of the canister. Multichannel syringe pumps (Soil Moisture Systems, Precision Multichannel Syringe Pump) provide pulsed injections of constant volume. Each pump supports ten syringes (10 mL syringe capacity), with each pump stroke transmitting a volume of nominally $5 \mathrm{~mL}$ to each injection point in approximately 5 seconds. For the target injection rate of $250 \mathrm{~mL} / \mathrm{hr} / \mathrm{m}$ of canister length per hour $(1 \mathrm{~L} / \mathrm{hr}$ over the total $4 \mathrm{~m}$ canister length), the syringe pumps operate on approximately 9-minute intervals, controlled with a timer internal to the syringe pump. Each injection pump draws tracer solution from a $378.5-\mathrm{L}$ (100-gallon) plastic tank placed on a platform scale.

\section{PRETEST PREDICTIONS}

Pretest predictions of the performance of the capillary barrier and plain backfill configurations were performed with the TOUGH2 code (Pruess, 1991) in order to try to understand the response of the systems. A simplified rectangular model of the canister was used for this task, which is shown in Figure 2. Only half of the canister was modeled due to symmetry. The top part of the model (0-0.3 m depth) represents the fine layer in the capillary barrier configuration, while the bottom part $(0.3-1.3 \mathrm{~m}$ depth) contains the coarse material. The meshing is finer near the fine-coarse interface and at the bottom of the model. The model shown in Figure 2 is rotated 30 degrees clockwise, and wicks were introduced into the model on the right-hand vertical boundary at the bottom of the fine and coarse layers through the imposition of a constant suction potential. Water is injected at a constant rate at the upper left-hand corner. For the plain backfill configuration, the model remained the same except that the fine layer properties were replaced with coarse layer values. 




Figure 2. TOUGH2 Model for Pretest Predictions.

The results of the simulations are given in Figures 3 and 4 for the capillary barrier and plain backfill cases, respectively.

As can be seen from Figure 3 for the capillary barrier case, the injected mass increases linearly due to the constant injection rate. Flow out of the system at the top wick, which is water from the fine (upper) layer, is predicted to start at about 15 days at a rate essentially equal to the injection rate. Therefore, the water stored in the system becomes essentially constant after this time. Flow out of the bottom wick, which is water from the coarse (lower) layer, is predicted to start at about 36 days at a negligible rate about two orders of magnitude lower than from the fine layer.

For the case of plain backfill, the pretest predictions are given in Figure 4. As in the instance of the capillary barrier case, the mass injected increases linearly with time. However, the timing and the location of flow out of the wicks are dramatically different. The flow out of the system starts at about

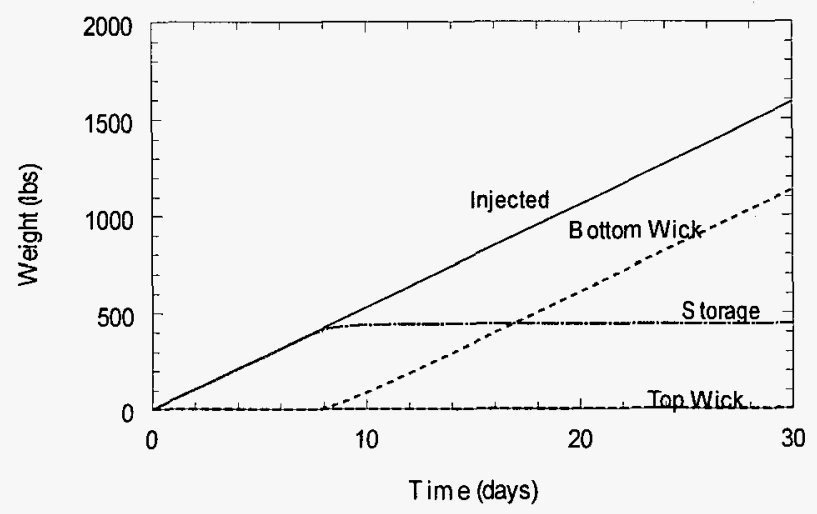

Figure 3. Capillary Barrier Pretest Predictions.

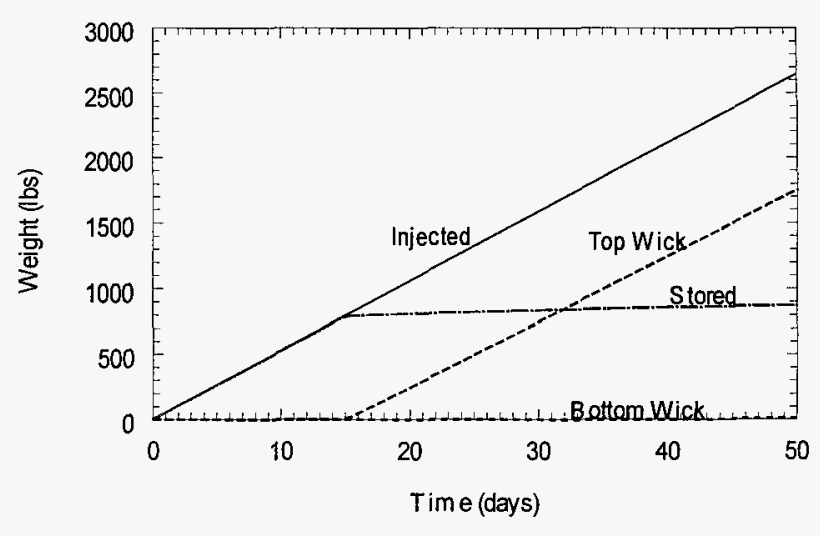

Figure 4. Plain Backfill Pretest Predictions.

8 days as opposed to 15 days for the capillary barrier case. In contrast to the capillary barrier case, almost all of the flow in the plain backfill situation occurs from the bottom wick. A much smaller amount of water (two orders of magnitude lower) is predicted to flow out of the top wick, which starts at about the same time as flow out of the bottom wick.

The results for the two cases are almost exactly opposite. For the capillary barrier configuration, $>99 \%$ of the effluent comes from the top wick. For the plain backfill case, $>99 \%$ of the effluent comes from the bottom wick. These pretest predictions show dramatically different performance of the system for the two cases.

As a result of the capillary diversion for the capillary barrier case, water is kept away from the region around the simulated waste package for a significant length of time. When moisture does increase around the waste package, the levels are only slightly above residual. In contrast, for plain backfill, the water essentially flows straight down to the waste package, increasing the moisture content in that region significantly.

\section{DATA}

The EBS Pilot Scale test data are presented for the capillary barrier and plain backfill configurations in terms of the water balance, which represents the accumulated injection, storage, and water removal. The specific data from each of the suites of gages are not presented here.

The water balance is represented by the balance of the weight of the injected water with the stored and effluent water. The water balance data are presented in Figures 5 through 8 for the capillary barrier and plain backfill configurations. The data shown in Figure 5 for the capillary barrier show that virtually all the injected water is accounted for in the water balance. The difference through day 70 represents 
only $1-2 \%$ of the total injected weight. After water starts to flow out of the system, the storage shows minor changes as the effluent parallels the injected mass.

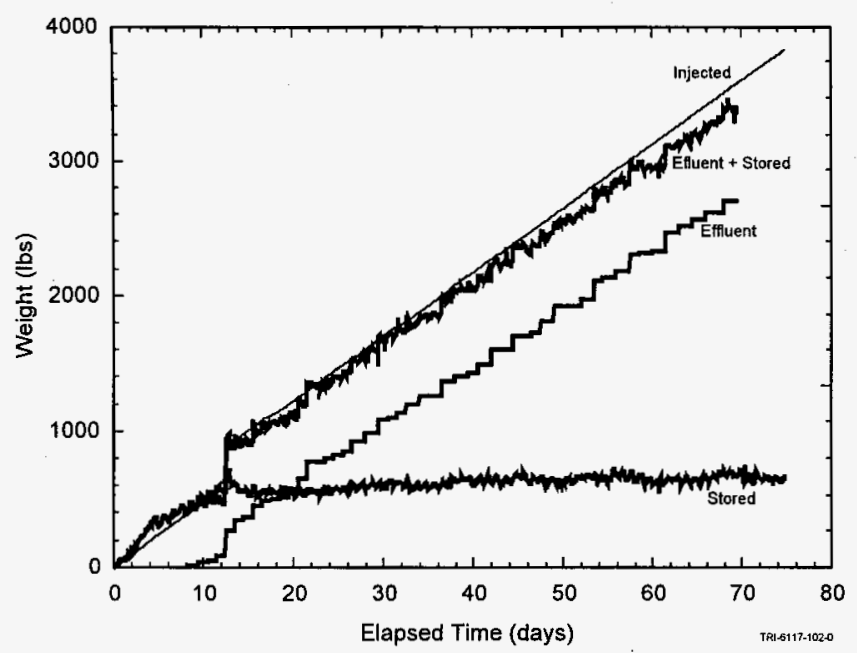

Figure 5. Water Balance Data for Capillary Barrier Configuration.

Figure 6 shows the distribution of the effluent. The wicks noted as left side top row and right side middle represent those wicks that were in direct contact with the fine capillary barrier layer. The difference in designation is because the wick configuration differed from the left to right sides. The suction lysimeters were located in the "channels" below the interface, and that water represents either breakthrough or communication flow from the fine-layer wicks. The other wicks are those at the bottom of the canister. The data show that most of the water effluent (>90\%) for the capillary barrier case is from the fine layer.

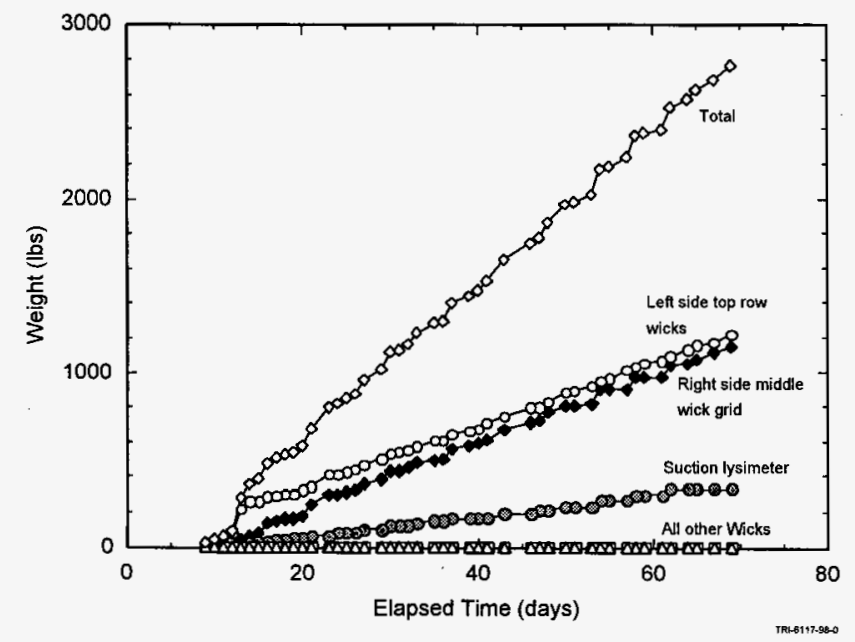

Figure 6. Distribution of Effluent for the Capillary Barrier Case.
The water balance for the plain backfill case is presented in Figure 7. These data show that about $90 \%$ of the injected water is accounted for in the water balance through day 34 , the day the injection was terminated. The difference is likely due to incomplete weighing and reporting of all collected effluent for the plain backfill case.

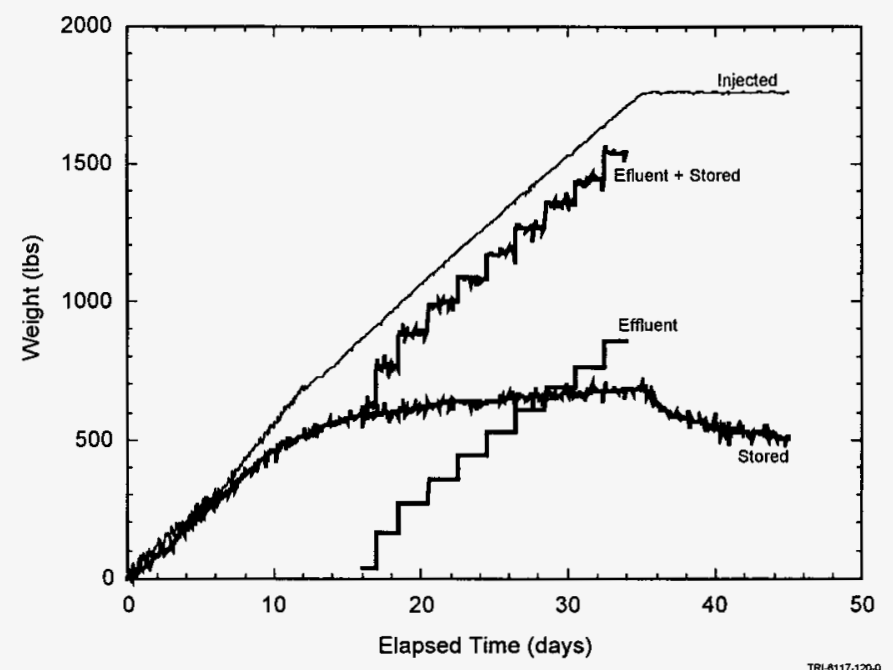

Figure 7. Water Balance Data for Plain Backfill Configuration.

Figure 8 gives the effluent distribution for the plain backfill configuration. The bottom front wicks represent water collected directly below the centerline of the simulated waste package. The "side" wicks are the bottommost wicks located along the sides of the canister and represent water collected by the wicks due to dispersion of the wetting front. The sum of these totals almost exactly matches total amount of effluent collected. There was essentially no effluent from the top wicks for this configuration.

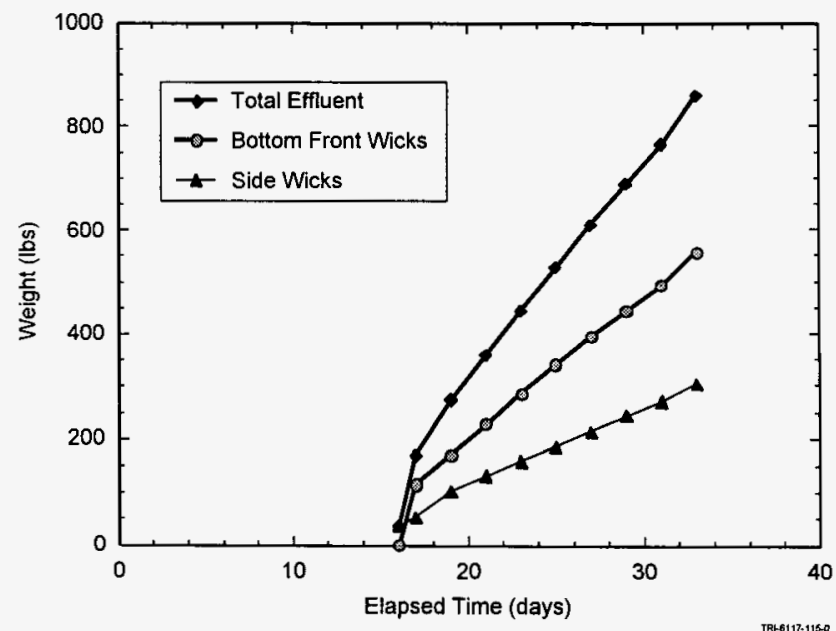

Figure 8. Distribution of Effluent for the Plain Backfill Case. 


\section{DATA-MODEL COMPARISONS}

The data and model pretest predictions compare reasonably well. For the capillary barrier case, essentially all of the water is predicted to flow out of the wicks in communication with the fine layer. The data show the same behavior. Quantification of the fraction flowing out of the fine layer is complicated by communication between the lysimeters and the fine layer wicks, but the predictions are in the possible range of the data. The timing of the start of the effluent is overpredicted in the pretest predicts (15 days for the model versus 8 days for the data), probably due to stratification in the fine layer as discussed in the next section.

For the plain backfill case, essentially all the water is predicted to flow out of the bottom wicks, which is supported by the experiments. The timing is again underpredicted ( 6 days for the model versus 14 days for the experiment). Note that the data show a mismatch between the injected water and the storage starting at about 6 days, while the effluent starts at 14 days. As mentioned earlier, the problem may be incomplete weighing and reporting of the effluent between 6 days and 14 days.

Overall, the pretest predictions and the experimental data match quite well, especially considering the simplicity of the model. Other differences include the variable injection rate in the test as indicated by the non-linearity of the injected mass.
Even with these differences, the model predicts the experimental data both qualitatively and quantitatively, thereby establishing confidence in the TOUGH2 code for the prediction of capillary barrier and plain backfill behavior.

\section{POSTTEST CHARACTERIZATION}

The capillary barrier configuration was disassembled carefully following completion of the testing in an attempt to determine the condition of the capillary interface and whether stratification could be observed. This is important in evaluating the measured data with the pretest model predictions. A sketch of the observed stratification is shown in Figure 9. This figure shows the stratification observed near the front face after the top front cover was removed. The figure shows two distinct darker layers roughly paralleling the top surface of the fine layer. The layers are each about $2 \mathrm{~cm}$ thick and about 1-2 $\mathrm{cm}$ below the top surface. On the left side there is an additional "darker" layer extending from the mid-slope angled toward the centerline of the can at the top of the coarse layer. It is possible that this stratification could partially explain the discrepancy in the initial pretest predictions and actual observations of the first arrival of moisture at the wicks at the canister boundary. This discrepancy may be due to heterogeneities such as those observed during the canister

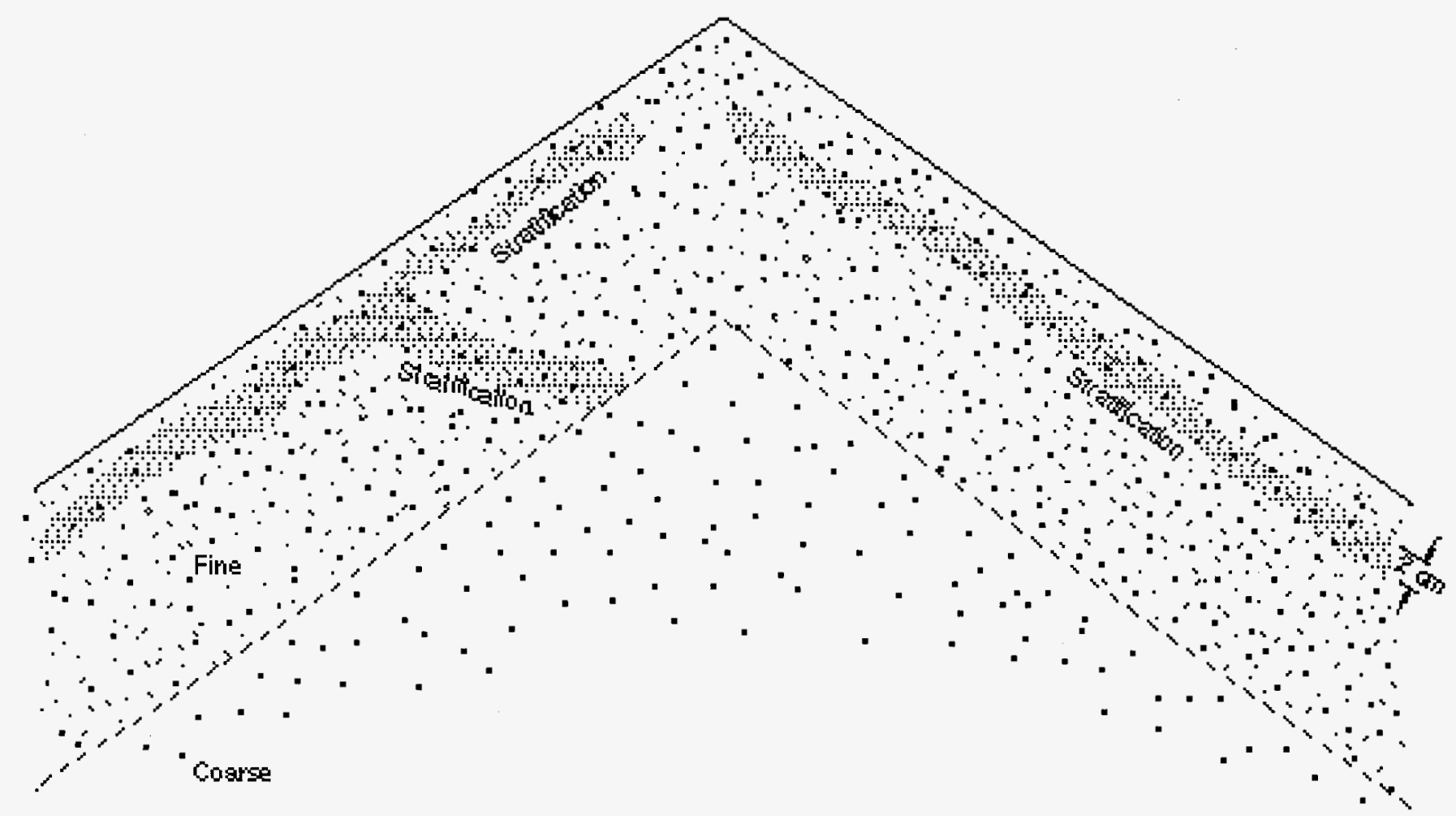

Figure 9. Stratification observed in the fine layer of the Capillary Barrier Configuration. 
disassembly. Anisotropy has been observed in hillside unsaturated flow similar to the fine layer by McCord et al. (1991). This behavior has not been included in the pretest predictions. It is unknown whether any significant amount of dyed water penetrated the fine layer into the underlying coarse layer, although no water was evident on the clear acrylic simulated waste package during the testing. Also, there was no evidence of penetration of the fine sand into the coarse fraction during the posttest evaluations.

\section{DISCUSSION}

The capillary barrier EBS configuration of a tilted fine sand layer overlying a coarse sand layer performed well under the testing conditions imposed. No visible liquid water was evident in the backfill surrounding the simulated waste package throughout the course of the test. With the exception of small amounts of water wicking into the coarse backfill component, the majority of the injected water was diverted toward the canister boundary by the sloping capillary interface. The capillary barrier configuration clearly shows promise as an engineered barrier where the intent is to divert the majority of any downward water percolation laterally away from the waste package into the underlying surrounding rock. The capillary barrier configuration conducted here also shows continued wetting of the system, probably due to wetting of the coarse layer by diffusion or other processes. The importance of this is unknown; however, it should be emphasized that no attempt was made to optimize the backfill materials used, and laboratory analyses of the coarse backfill show a relatively high percentage of fines, which would lead to greater wetting of the coarse layer than would be expected with a cleaner material.

The plain backfill EBS configuration with sloped top was visibly wet at the top of the clear acrylic visualization tube within three days from the start of the test. Water appeared at the bottom wick drains below the acrylic visualization tube within seven days from the start. The first effluent weights were collected on day 13. The majority of the effluent was captured by the bottom wick drains underneath the clear acrylic visualization tube. The remainder of the effluent was captured in the bottom rows of wick drains on either side of the canister. The data clearly show that the injected water primarily moved downward by gravity and laterally by diffusion and capillary processes around the simulated waste package. As with the coarse backfill used in the capillary barrier configuration, a significant percentage of fines exist in the material. These fines likely influenced the wetting up by diffusion or other processes of this material. The posttest excavation showed clearly a laterally expanding wetting front that had extended to within $10 \mathrm{~cm}$ of the canister surface at the midpoint.

The TOUGH2 pretest predictions show qualitative and quantitative agreement with the experimental data, thereby establishing confidence in the TOUGH2 code for the prediction of capillary barrier and plain backfill behavior.

The two EBS experiments described here have provided data and observations to support the $\mathrm{Li}$ cense Application Design Selection effort. In particular, the $1 / 4$ scale experiments provide the opportunity to observe water movement in potential backfill systems at a scale large enough to incorporate heterogeneities and three-dimensional effects.

\section{REFERENCES}

Conca, J.L., Apted, M.J., Zhou, W., Arthur, R.C. \& Kessler, J.H. 1998. Flow barrier system for long-term high-levelwaste isolation: Experimental results. Nuclear Technology, 124 (1) 88-99. La Grange Park, Illinois: American Nuclear Society.

Fernandez, J.A. \& Richardson, A.M. 1994. A Review of the Available Technologies for Sealing a Potential Underground Nuclear Waste Repository at Yucca Mountain, Nevada. SAND93-3997. Albuquerque, New Mexico: Sandia National Laboratories.

Ho, C.K. \& Webb, S.W. 1998a. Capillary barrier performance in heterogeneous porous media. Water Resources Research, 34 (4) 603-609. Washington, DC: American Geophysical Union.

Ho, C.K. \& Webb, S.W. 1998b. The effects of heterogeneities and wavy interfaces on capillary barrier performance. Proceedings of the TOUGH Workshop '98, Lawrence Berkeley National Laboratory, Berkeley, California, May 46, 1998, LBNL-41995, CONF-980559, 216-221. Editor: Pruess, K. Berkeley, California: Earth Sciences Division, Lawrence Berkeley National Laboratory, University of California.

Kaviany, M. 1991. Principles of Heat Transfer in Porous Media. New York, New York: Springer-Verlag.

McCord, J.T., Stephens, D.B., \& Wilson, J.L. 1991. Hysterysis and state-dependent anisotropy in modeling unsaturated hillslope unsaturated hydrologic processes. Water Resources Research, 27 (7) 1501-1518. Washington, DC: American Geophysical Union.

Oldenburg, C.M. \& Pruess, K. 1993. On numerical modeling of capillary barriers. Water Resources Research, 29 (4) 1045-1056. Washington, DC: American Geophysical Union.

Pruess, K. 1991. TOUGH2-A General-Purpose Numerical Simulator for Multiphase Fluid and Heat Flow. LBL29400. Berkeley, California: Lawrence Berkeley Laboratory.

Ross, B. 1990. The diversion capacity of capillary barriers. Water Resources Research, 26 (10) 2625-2629. Washington, DC: American Geophysical Union. 
Ryder, E.E., Finley, R.E., George, J.T., Ho, C.K., Longenbaugh, R.S., \& Connolly, J.R. 1995. Bench-Scale Experimental Determination of the Thermal Diffusivity of Crushed Tuff. SAND94-2320. Albuquerque, New Mexico: Sandia National Laboratories.

Stormont, J.C. 1995a. The effect of constant anisotropy on capillary barrier performance. Water Resources Research, 31 (3) 783-785. Washington, DC: American Geophysical Union.

Stormont, J.C. 1995b. The performance of two capillary barriers during constant infiltration. Landfill ClosuresEnvironmental Protection and Land Recovery, Proceedings, San Diego, California, October 23-27, 1995, Geotechnical Special Technical Publication No. 53, 77-92. Editors: Dunn, R.J. \& Singh, U.P. New York, New York: American Society of Civil Engineers.

Tidwell, V.C. \& Glass, R.J. 1994. X ray and visible light transmission for laboratory measurement of twodimensional saturation fields in thin-slab systems. Water Resources Research, 30 (11) 2873-2882. Washington DC: American Geophysical Union.

Webb, S.W. 1997a. Generalization of Ross' tilted capillary barrier diversion formula for different two-phase characteristic curves. Water Resources Research, 33 (8) 1855-1859. Washington, DC: American Geophysical Union.

Webb, S.W. 1997b. Comparison of Ross' capillary barrier diversion formula with detailed numerical simulations. International Containment Technology Conference, St. Petersburg, Florida, February 9-12, 1997, CONF-970208Proc., 289-295. Washington, DC: U.S. Department of Energy.

Webb, S.W., McCord, J.T. \& Dwyer, S.F. 1997. Prediction of tilted capillary barrier performance. International Containment Technology Conference, St. Petersburg, Florida, February 9-12, 1997, CONF-970208-Proc. 296302. Washington, DC: U.S. Department of Energy.

\section{ACKNOWLEDGMENT}

This work described in this paper was supported by the U.S. Department of Energy under Contract DE-AC01-91RW00134 with Sandia National Laboratories, a multiprogram laboratory operated by Sandia Corporation, a Lockheed Martin Company.

\section{DISCLAIMER}

This paper was prepared as an account of work sponsored by an agency of the United States Government. Neither the United States Government nor any agency thereof, nor any of their employees, nor any of their contractors, subcontractors or their employees, makes any warranty, express or implied, or assumes any legal liability or responsibility for the accuracy, completeness, or any third party's use or the results of such use of any information, apparatus, product, or process disclosed, or represents that its use would not infringe privately owned rights. Reference herein to any specific commercial product, process, or service by trade name, trademark, manufacturer, or otherwise, does not necessarily constitute or imply its endorsement, recommendation, or favoring by the United States Government or any agency thereof or its contractors or subcontractors. The views and opinions of authors expressed herein do not necessarily state or reflect those of the United States Government or any agency thereof. 